Chronic Obstructive Pulmonary Diseases: Journal of the COPD Foundation

\author{
Original Research
}

\title{
Health-Related Quality of Life Improvements in Moderate to Very Severe Chronic Obstructive Pulmonary Disease Patients on Nebulized Glycopyrrolate: Evidence from the GOLDEN Studies
}

\author{
Gary T. Ferguson, MD ${ }^{1}$ Edward M. Kerwin, $\mathrm{MD}^{2}$ James F. Donohue, MD ${ }^{3}$ Vaidyanathan Ganapathy, $\mathrm{PhD}^{4}$ \\ Robert L. Tosiello, $\mathrm{MS}^{4}$ Vamsi K. Bollu, $\mathrm{PhD}^{5}$ Krithika Rajagopalan, $\mathrm{PhD}^{4}$
}

\section{Abstract}

Background: Symptoms of chronic obstructive pulmonary disease (COPD) may diminish patients' healthrelated quality of life (HRQoL). We report effects of Longhala ${ }^{\mathrm{TM}}$ Magnair ${ }^{\mathrm{TM}}$ (glycopyrrolate) Inhalation Solution, a drug/device combination of the long-acting antimuscarinic glycopyrrolate administered using the eFlow ${ }^{\circledR}$ closed system (eFlow CS) nebulizer, on HRQoL from the Glycopyrrolate for Obstructive Lung Disease Via Electronic Nebulizer (GOLDEN) clinical studies.

Methods: Data consisted of a pooled analysis of 2 phase 3, 12-week efficacy studies (GOLDEN-3 and -4) of glycopyrrolate/eFlow CS (25 or $50 \mathrm{mcg}$ twice daily [BID]) versus placebo, and a 48-week, open-label safety study (GOLDEN-5) of glycopyrrolate/eFlow CS 50 mcg BID versus tiotropium 18 mcg once daily in patients with moderate to very severe COPD. Change from baseline in HRQoL was measured via the St George's Respiratory Questionnaire (SGRQ). Results are provided as mean changes in SGRQ Total score and as response analysis ( $\geq 4$-point improvement [responder], no change, and $\geq 4$-point worsening in Total score) using analysis of covariance or logistic regression, as applicable.

Results: A total of 1293 patients were evaluated from GOLDEN-3 and -4 and 1086 from GOLDEN-5. Glycopyrrolate/eFlow CS significantly improved SGRQ Total and component scores. The percentage of SGRQ responders in pooled GOLDEN-3/4 was $46.8 \%$ for glycopyrrolate/eFlow CS 25 mcg, 41.7\% for glycopyrrolate/ eFlow CS 50 mcg, and 34.5\% for placebo. SGRQ Total and component score improvements were similar between glycopyrrolate/eFlow CS and tiotropium in GOLDEN-5.

Conclusions: The drug/device combination of glycopyrrolate/eFlow CS significantly improved HRQoL, as measured by the SGRQ, offering a potential maintenance treatment option in patients with moderate to very severe COPD.

ClinicalTrials.gov: NCT02347761, NCT02347774, NCT02276222

\footnotetext{
Abbreviations: chronic obstructive pulmonary disease, COPD; health-related quality of life, HRQoL; eFlow ${ }^{\circledR}$ Closed System nebulizer, eFLOW CS; Glycopyrrolate for Obstructive Lung Disease Via Electronic Nebulizer trial, GOLDEN; twice daily, BID; St George's Respiratory Questionnaire, SGRQ; long-acting beta2-agonist, LABA; long-acting muscarinic antagonist, LAMA; dry powder inhaler, DPI; peak inspiratory flow rates, PIFR; forced expiratory volume in 1 second, FEV $_{\mathbf{1}}$; forced vital capacity, FVC; cardiovascular, CV; metered-dose inhaler, $\mathbf{M D I}$; minimum clinically important difference, MCID; least squares, LS; standard error, SE; confidence interval, CI

Funding Support: Sunovion Pharmaceuticals Inc., provided funding for this research.

Date of Acceptance: March 14, 2018

Citation: Ferguson GT, Kerwin EM, Donohue JF, et al. Health-related quality of life improvements in moderate to very severe chronic obstructive pulmonary disease patients on nebulized glycopyrrolate: evidence from the GOLDEN studies. Chronic Obstr Pulm Dis. 2018;5(3):193-207. doi: https://doi.org/10.15326/jcopdf.5.3.2017.0178
} 


\begin{tabular}{|c|c|}
\hline & $\begin{array}{l}\text { Pulmonary Research Institute of Southeast Michigan, Farmington } \\
\text { Hills }\end{array}$ \\
\hline & Clinical Research Institute of Southern Oregon, PC, Medford \\
\hline & University of North Carolina School of Medicine, Chapel Hill \\
\hline & Sunovion Pharmaceuticals Inc., Marlborough, Massachusetts \\
\hline
\end{tabular}

\section{Address correspondence to:}

Gary T. Ferguson, MD

Pulmonary Research Institute of Southeast Michigan

29255 West 10 Mile Road, Suite A

Farmington Hills, MI 48336

Tel: (248) 478-6561

Fax: (248) 478-6908

Email: garytferguson@msn.com

\section{Keywords:}

chronic obstructive pulmonary disease; COPD; nebulizer; longacting muscarinic antagonist; health status; health-related quality of life; HRQoL

\section{Introduction}

Chronic obstructive pulmonary disease (COPD) is characterized by progressive airflow limitation, persistent respiratory symptoms, high morbidity and mortality, and significant health care costs. ${ }^{1}$ COPD is generally caused by significant exposure to noxious particles; cigarette smoking is the primary environmental risk factor in the industrialized world. ${ }^{1}$ The World Health Organization estimates that 65 million people worldwide suffer from moderate to severe COPD, and that COPD was the cause of 3 million deaths in $2015 .^{2,3}$ In the United States, nearly 27 million people are affected by COPD, and it is the third leading cause of death. ${ }^{4,5}$

The most common symptoms of COPD include dyspnea, chronic cough, and sputum production. ${ }^{1}$ These symptoms can contribute to activity limitation, fatigue, anxiety, depression, and insomnia. ${ }^{6,7}$ Studies have demonstrated that patients with COPD have diminished physical and mental health-related quality of life (HRQoL) and that HRQoL worsens as the disease progresses. ${ }^{8,9}$ Studies have also reported a significant association between COPD exacerbations and HRQoL. ${ }^{10-12}$ In patients with severe to very severe COPD, diminished HRQ $\mathrm{H}$ has been shown to persist for up to 12 months after an acute symptomatic exacerbation. ${ }^{13}$ Goals of COPD therapy are to improve symptoms, make exacerbations less frequent and less severe, increase exercise tolerance, and improve overall health status. ${ }^{1}$ Long-acting bronchodilators, including long-acting beta2-agonists (LABAs) and long-acting muscarinic antagonists (LAMAs) are the cornerstone of COPD disease maintenance therapy. LABAs and LAMAs have produced significant improvements in lung function and $H R Q O L$ in clinical trials of patients with COPD. ${ }^{14-16}$ LABA and LAMA agents are generally administered by inhalation using handheld inhalers or nebulizers. ${ }^{17}$ The most commonly used inhalation devices are handheld inhalers, including pressurized metered-dose inhalers (pMDIs), dry powder inhalers (DPIs), and soft mist inhalers. Handheld inhalers are generally small, lightweight, and easily portable, but hand-breath coordination, and for DPIs, an optimal inspiratory effort, is needed from patients for effective inhalation. ${ }^{18,19}$ Use of handheld inhalers may also be challenging for patients with cognitive impairment or physical disabilities affecting motor coordination. ${ }^{20,21}$ Older age has also been associated with poor inhaler technique. ${ }^{1}$ In addition, as many as 1 in 5 older patients may be unable to generate sufficient peak inspiratory flow rates (PIFR) for successful use of a DPI. ${ }^{22-24}$

Nebulizers that deliver drugs via repeated inhalations of a nebulized mist have several design advantages over handheld devices. These advantages include allowing use during tidal (or normal) breathing, lack of need for timing and coordination, and less need for inspiratory effort during inhalation. ${ }^{25}$ Nebulizers may be more suitable for patients with severe disease, poor hand-breath coordination, and those who cannot generate adequate inspiratory effort. ${ }^{26}$ Nebulized medications for COPD are typically administered via a jet nebulizer, which can be bulky and require an external power source plus considerable administration time. ${ }^{25}$ The development of newer nebulizers for respiratory and other conditions, including vibrating mesh and membrane nebulizers, offer some design advantages as compared with jet nebulizers - these new nebulizers are battery operated, portable, and have reduced administration times. ${ }^{25-28}$ Although nebulizers are approved for use with a variety of respiratory medications, there is currently no LAMA available in a nebulized form. Lonhala ${ }^{\mathrm{TM}}$ Magnair $^{\mathrm{TM}}$ (glycopyrrolate) Inhalation Solution, recently approved for commercial use at the 25-mcg dose in COPD patients, is a drug/ device combination providing nebulized delivery of a LAMA: glycopyrrolate administered using the eFlow ${ }^{\circledR}$ closed system (hereafter referred to as eFlow CS) nebulizer (PARI Pharma GmbH; Starnberg, Germany). 
The eFlow CS is a portable, virtually silent nebulizer system with a vibrating membrane. It is designed to deliver a fine mist with uniform particle size, a respirable fraction suitable for central and peripheral deposition, and consistent dose of glycopyrrolate in 2-3 minutes. $^{27}$

Glycopyrrolate/eFlow CS was evaluated in 3 pivotal studies in patients with moderate to very severe COPD, known as the Glycopyrrolate for Obstructive Lung Disease Via Electronic Nebulizer (GOLDEN) trials. GOLDEN-3 and GOLDEN-4 were phase 3, randomized, double-blind, placebo-controlled, 12-week studies of glycopyrrolate/eFlow CS versus placebo. GOLDEN-5 was a 48-week, randomized, open-label, parallel-group safety study of glycopyrrolate/eFlow CS versus tiotropium. Efficacy and safety data of glycopyrrolate/eFlow CS from the individual studies have been reported elsewhere. ${ }^{29,30}$ In this article we report findings from all 3 GOLDEN studies regarding the impact of glycopyrrolate/eFlow CS on HRQoL as measured by the St George's Respiratory Questionnaire (SGRQ). While analyses of SGRQ from the pooled GOLDEN-3 and -4 studies will show the impact of nebulized glycopyrrolate on HRQoL versus placebo at the 12-week time point, analyses of GOLDEN-5 data were aimed at evaluating consistency of the HRQOL effect of treatment at multiple visits over 48 weeks and to compare the HRQoL impact of this new treatment with an already established LAMA drug, tiotropium.

\section{Methods}

Patient-reported HRQoL data are from a pooled analysis of the pivotal GOLDEN-3 (NCT02347761) and GOLDEN-4 (NCT02347774) studies, and a separate analysis of the long-term GOLDEN-5 study (NCT02276222). All procedures followed the Declaration of Helsinki and received institutional review board approval. All patients or their legal representatives gave written, informed consent.

\section{Inc/usion/Exc/usion Criteria}

Patient criteria for the GOLDEN studies have been previously presented. ${ }^{27,29}$ Briefly, patients $\geq 40$ years of age, with moderate to very severe COPD per the 2014 report of the Global Initiative for Chronic Obstructive Lung Disease (GOLD) ${ }^{31}$ and who were current or former smokers with a smoking history of $\geq 10$ pack years were included. Pulmonary function required at screening included post-bronchodilator (following inhalation of ipratropium bromide 68 $\mu \mathrm{g} ; 4$ puffs of $17 \mu \mathrm{g}$ ) forced expiratory volume in 1 second $\left(F E V_{1}\right)$ of $<80 \%$ of predicted normal and $>0.7$ $\mathrm{L}$, and $\mathrm{FEV}_{1} /$ forced vital capacity $(\mathrm{FVC}$ ) ratio $<0.70$. Patients were excluded from the studies if they had a history of or current unstable cardiac disease or long QT syndrome, clinically significant respiratory disease other than COPD, and recent history of COPD exacerbation requiring hospitalization or need for increased treatments for COPD within 6 weeks prior to screening.

\section{Study Design}

Design of the GOLDEN studies are presented in Figures $1 \mathrm{a}$ and $1 \mathrm{~b}$. The inclusion of patients with very severe disease (post-bronchodilator $\mathrm{FEV}_{1} \%$ predicted $<30 \%$ ) and those with a history of cardiovascular (CV) disease (including hypertension, ischemic heart disease, cerebrovascular disease, peripheral arterial disease, clinically significant arrhythmia, and heart failure) was permitted to reflect the general COPD population. Background LABA therapy was allowed in up to $30 \%$ of patients in GOLDEN-3 and -4 and with no limit in GOLDEN-5.

Following an initial screening period, patients were randomized (using a web/voice interactive response system) 1:1:1 to glycopyrrolate/eFlow CS $25 \mathrm{mcg}$ twice daily (BID), glycopyrrolate/eFlow CS $50 \mathrm{mcg}$ BID, or placebo BID in GOLDEN-3 and -4 , and 4:3 to glycopyrrolate/eFlow CS 50 mcg BID or tiotropium $18 \mathrm{mcg}$ once daily (via HandiHaler ${ }^{\mathrm{TM}}$ ) in GOLDEN-5 (Figure 2). Glycopyrrolate/eFlow CS and placebo were administered daily in the morning and evening. Tiotropium was administered daily in the morning. In GOLDEN-3 and -4, patients, investigators, site staff, and the study sponsor were blinded to all treatments during the treatment period. An albuterol metereddose inhaler (MDI) was provided to all patients and permitted as rescue medication for as-needed use any time during the study assessments; in the case of continued symptom exacerbation, a supplemental ipratropium bromide MDI was provided. Other LAMAs or short-acting bronchodilators were not permitted.

High CV risk was defined as patients with pre-existing diagnosis of ischemic heart disease, cerebrovascular disease, peripheral arterial disease, hypertension, clinically significant arrhythmia, and/or heart failure. 


\section{St George's Respiratory Questionnaire}

The SGRQ is a validated, COPD-specific patientreported outcome instrument designed to measure and quantify the impact of disease on HRQoL in patients with chronic airflow limitation. The SGRQ consists of 50 items that yield a Total score (effect of disease on overall HRQOL) based on a sum of the total number of items, as well as 3 component scores: Symptoms (frequency and severity of respiratory symptoms), Activity (disturbance or limitations to daily physical activities), and Impacts (psychosocial function disturbances due to airway disease). Scores range from 0 (no impairment) to 100 (maximum impairment). ${ }^{32}$ The minimum clinically important difference (MCID) is a general threshold used to determine whether an intervention provides a clinical benefit. ${ }^{33}$ The MCID

\section{Figure 1a. GOLDEN-3 and -4 Study Design}

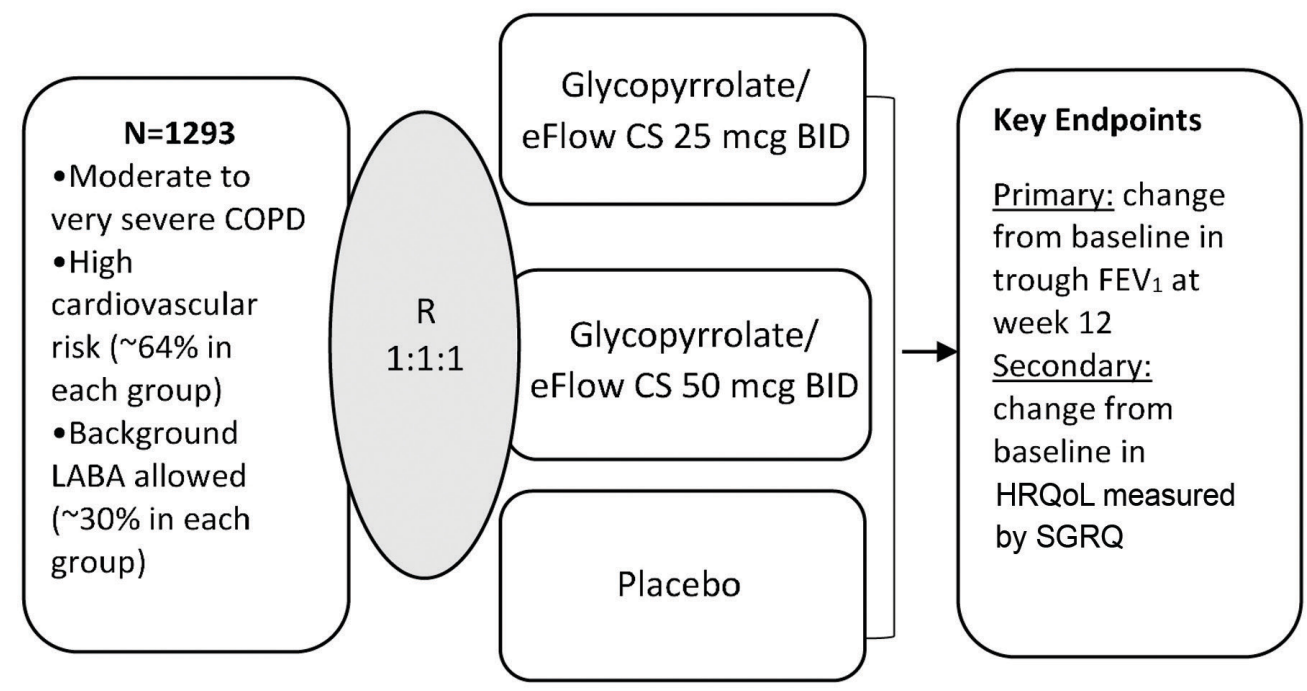

12-week, randomized, double-blind, placebo-controlled, efficacy and safety trials

\section{Figure 1b.GOLDEN-5 Study Design}

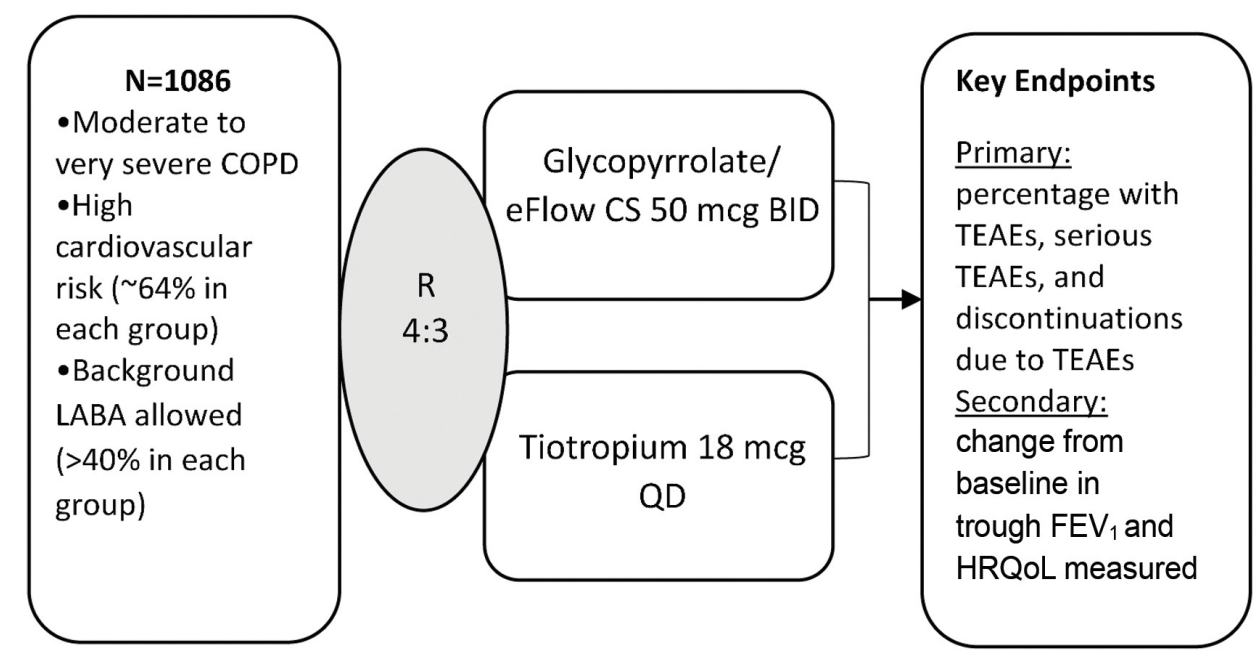

48-week, randomized, open-label, parallel-group safety trial

$\mathrm{BID}=$ twice daily; $\mathrm{COPD}=$ chronic obstructive pulmonary disease; $\mathrm{FEV}_{1}=$ forced expiratory volume in 1 second; HRQoL=health-related quality of life; LABA=long-acting beta2-agonist; $Q D=$ once daily;

$\mathrm{R}=$ randomization; $\mathrm{SGRQ}=\mathrm{St}$ George's Respiratory Questionnaire; TEAE=treatment-emergent adverse event for the SGRQ is a 4-point improvement (reduction) in Total score. ${ }^{34}$ A key secondary efficacy endpoint in the GOLDEN studies was change from baseline in SGRQ score (Figures 1a and 1b). SGRQ assessments were conducted at baseline (week 0) and at week 12 in GOLDEN-3, -4, and -5 . The SGRQ was also assessed at weeks 24 and 48 in GOLDEN-5. Assessments were completed at the end of treatment for patients who were unable to complete the study.

\section{Statistical Methods}

Change from baseline in SGRQ Total score and each component score were analyzed using analysis of covariance, with change from baseline as the response variable and with factors for treatment group, high-risk CV comorbidities (yes/no), background LABA use (yes/no), and baseline score as covariates. Baseline scores for each SGRQ component and Total score were calculated from the latest SGRQ assessment taken prior to the first dose of study medication. Proportion of responders on SGRQ Total score was defined by MCID criteria ( $\geq-4$-unit change from baseline). SGRQ response was 


\section{Figure 2. Study Schematic}

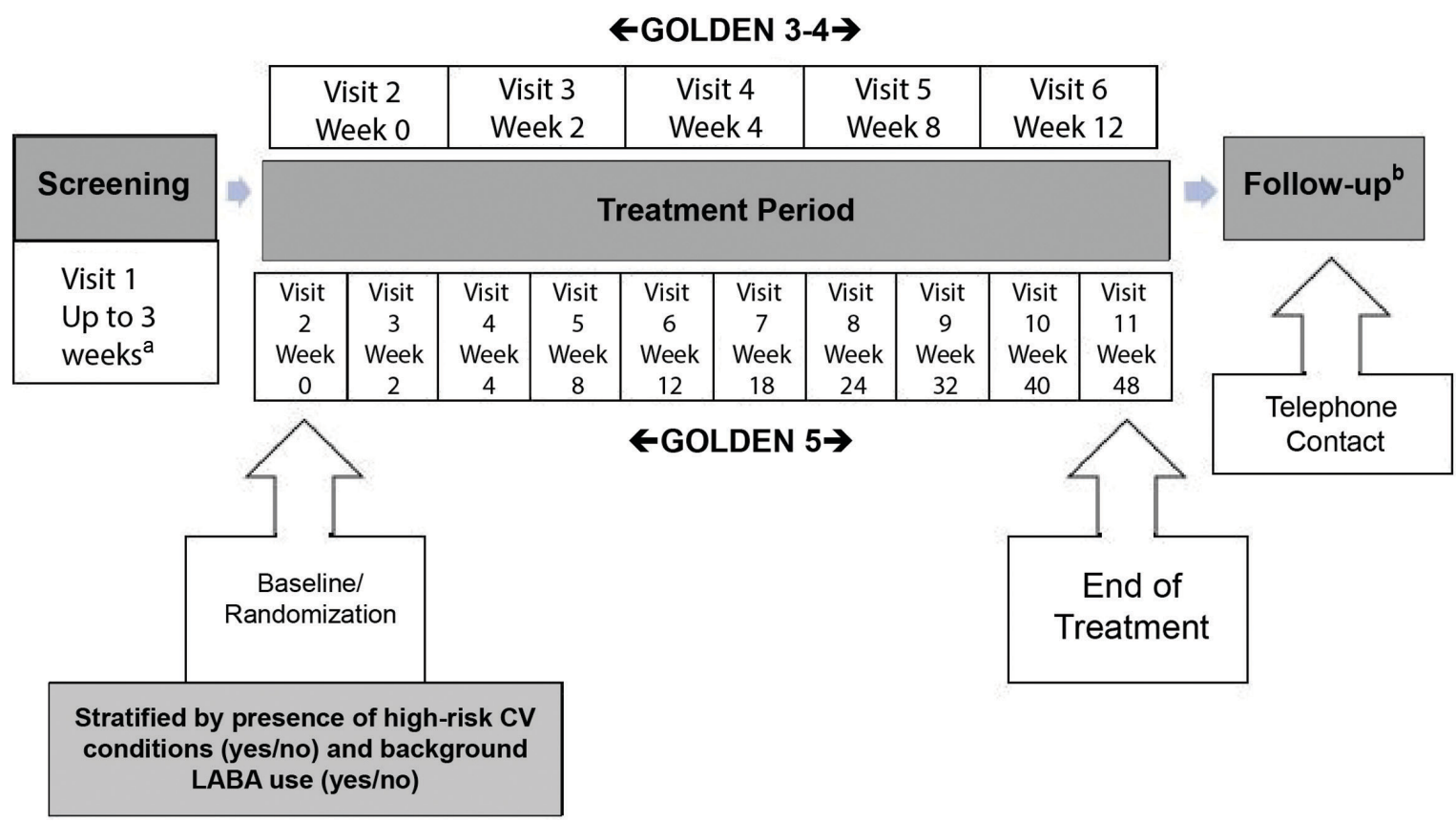

\footnotetext{
aVisit 1 may have occurred over more than 1 clinic visit and may have been up to 3 weeks, but must have been a minimum of 1 week, prior to randomization (visit 2) to ensure that at least 1 week of rescue medication use and COPD symptoms were recorded prior to randomization.

${ }^{b}$ All patients were contacted by telephone 5-7 days after the last study visit or at end of treatment for a final safety assessment. $\mathrm{COPD}=$ chronic obstructive pulmonary disease; $\mathrm{CV}=$ cardiovascular; LABA=long-acting beta2-agonist
}

further analyzed to include patients with no change $(-4<$ change $<4)$ and worsening of Total score $(\geq 4$-point increase). The odds ratio for response was determined using a logistic regression model. In GOLDEN -3 and -4 , responders were also evaluated by subgroups: age (40-50, $\geq 65,<65, \geq 75$ ), post-bronchodilator $\mathrm{FEV}_{1} \%$ predicted $(<50 \%$ and $\geq 50)$, In-Check ${ }^{\mathrm{TM}}$ PIFR $(\geq 60 \mathrm{~L} / \mathrm{min}$ and $<60 \mathrm{~L} / \mathrm{min}$ ), and background LABA use (yes or no). For the pooled GOLDEN-3 and -4 data, results presented are for the intent-to-treat population using on-treatment data (from first date of study drug to last date of study drug). GOLDEN-5 was a safety study; therefore, results are presented from the intent-totreat population in all patients who were randomized to treatment and received at least 1 dose of study medication. The alpha level for these analyses was set at 0.05 without adjustment for multiplicity and all analyses were conducted using SAS 9.3 (SAS Institute, Cary, North Carolina).

\section{Results}

\section{Patient Characteristics and Disposition}

In GOLDEN-3 and -4, a total of 1293 patients were randomized to either glycopyrrolate/eFlow CS $25 \mathrm{mcg}$ (n=431), glycopyrrolate/eFlow CS $50 \mathrm{mcg}(\mathrm{n}=432)$, or placebo $(\mathrm{n}=430)$. The proportions of patients who completed the studies were 91.9\% ( $n=396), 92.6 \%$ $(n=400)$, and $88.1 \% \quad(n=379)$ for glycopyrrolate/ eFlow CS 25 mcg, glycopyrrolate/eFlow CS 50 mcg, and placebo, respectively. As shown in Table 1 , a majority of patients were white (89.6\%), current smokers (52.9\%), and had $\geq 1$ high-risk CV condition at baseline. Mean baseline SGRQ Total scores were similar among treatment groups and indicated high symptom burden and poor COPD-related health status in these groups (glycopyrrolate/eFlow CS 25 mcg: 49.25, glycopyrrolate/eFlow CS 50 mcg: 49.24, and placebo: 48.02; Table 1).

In GOLDEN-5, a total of 1086 patients were randomized to the glycopyrrolate/eFlow CS ( $\mathrm{n}=620)$ and the tiotropium ( $\mathrm{n}=466)$ groups. The proportion of patients who completed the study were $70.3 \%(n=436)$ 


\section{Table 1. Baseline Patient Demographics and Clinical Characteristics}

\begin{tabular}{|c|c|c|c|c|c|}
\hline \multirow[b]{2}{*}{ Demographic } & \multicolumn{3}{|c|}{ GOLDEN-3 and -4 } & \multicolumn{2}{|c|}{ GOLDEN-5 } \\
\hline & $\begin{array}{l}\text { Placebo } \\
(n=430)\end{array}$ & $\begin{array}{c}\text { Glycopyrrolate/ } \\
\text { eFlow CS } 25 \text { mcg } \\
\text { (n=431) }\end{array}$ & $\begin{array}{c}\text { Glycopyrrolate/ } \\
\text { eFlow CS } 50 \mathrm{mcg} \\
(n=432)\end{array}$ & $\begin{array}{l}\text { Tiotropium } 18 \mathrm{mcg} \\
\qquad(\mathrm{n}=466)\end{array}$ & $\begin{array}{c}\text { Glycopyrrolate/ } \\
\text { eFlow CS } 50 \mathrm{mcg} \\
(\mathrm{n}=620)\end{array}$ \\
\hline Age, mean (SD) & $63.7(8.81)$ & $63.3(8.71)$ & $62.6(8.64)$ & $63.3(9.0)$ & $63.3(8.5)$ \\
\hline Female, n (\%) & $195(45.3)$ & $189(43.9)$ & $185(42.8)$ & $206(44.2)$ & $270(43.5)$ \\
\hline \multicolumn{6}{|l|}{ Race, n (\%) } \\
\hline White & 388 (90.2) & 385 (89.3) & 386 (89.4) & 436 (93.6) & 582 (93.9) \\
\hline Black or African heritage & $39(9.1)$ & $42(9.7)$ & $44(10.2)$ & $27(5.8)$ & $35(5.6)$ \\
\hline Body mass index, $\mathrm{kg} / \mathrm{m}^{2}$, mean $(\mathrm{SD})$ & $29.02(6.9)$ & $28.26(6.9)$ & $28.41(6.5)$ & $28.63(6.6)$ & $28.45(6.2)$ \\
\hline $\begin{array}{l}\text { Number of COPD exacerbations } \\
\text { within } 12 \text { months, mean (SD) }\end{array}$ & $0.4(2.67)$ & $0.2(0.56)$ & $0.3(2.42)$ & $0.4(3.1)$ & $0.3(0.7)$ \\
\hline History of oxygen use - yes, n (\%) & $20(4.7)$ & $32(7.4)$ & $18(4.2)$ & $22(4.7)$ & $30(4.8)$ \\
\hline High cardiovascular risk, $\mathrm{n}(\%)^{\mathrm{a}}$ & $278(64.7)$ & $275(63.8)$ & $275(63.7)$ & $297(63.7)$ & $401(64.7)$ \\
\hline Background LABA use - yes, n (\%) & $132(30.7)$ & $135(31.3)$ & $135(31.3)$ & $192(41.2)$ & $267(43.1)$ \\
\hline Inhaled corticosteroid - yes, n (\%) & $127(29.5)$ & $126(29.2)$ & $122(28.2)$ & $165(35.4)$ & $225(36.3)$ \\
\hline \multicolumn{6}{|l|}{ Smoking status, n (\%) } \\
\hline Current & $218(50.7)$ & $240(55.7)$ & $226(52.3)$ & 239 (51.3) & $330(53.2)$ \\
\hline Former & $212(49.3)$ & $191(44.3)$ & $206(47.7)$ & $227(48.7)$ & $290(46.8)$ \\
\hline \multicolumn{6}{|c|}{ Pulmonary function tests (post-bronchodilator), mean (SD) } \\
\hline FVC, L & $2.783(0.7)$ & $2.791(0.8)$ & $2.825(0.8)$ & $2.848(0.8)$ & $2.812(0.8)$ \\
\hline $\mathrm{FEV}_{1}, \mathrm{~L}$ & $1.521(0.5)$ & $1.514(0.5)$ & $1.533(0.5)$ & $1.532(0.5)$ & $1.503(0.5)$ \\
\hline $\mathrm{FEV}_{1} / \mathrm{FVC}(\%)$ & $54.6(9.8)$ & $54.3(10.0)$ & $54.2(10.2)$ & $53.7(10.2)$ & $53.5(10.1)$ \\
\hline $\mathrm{FEV}_{1}$ percent predicted (\%) & $52.1(13.6)$ & $52.0(14.2)$ & $51.1(14.3)$ & $51.7(13.5)$ & $51.0(13.6)$ \\
\hline \multicolumn{6}{|l|}{ Post-bronchodilator FEV $_{1}, \mathrm{n}(\%)$} \\
\hline$<30 \%$ predicted & $24(5.6)$ & $29(6.7)$ & $35(8.1)$ & $26(5.6)$ & $37(6.0)$ \\
\hline$\geq 30 \%$ predicted to $<50 \%$ predicted & $153(35.6)$ & $156(36.2)$ & $158(36.6)$ & $170(36.5)$ & $245(39.5)$ \\
\hline$\geq 50 \%$ predicted & $253(58.8)$ & $245(56.8)$ & $239(55.3)$ & $270(57.9)$ & $338(54.5)$ \\
\hline Baseline In-Check ${ }^{\mathbf{b}}$ PIFR (L/min) & $87.8(31.5)$ & $86.1(32.6)$ & $85.1(31.9)$ & $77.9(32.5)$ & $78.2(32.4)$ \\
\hline \multicolumn{6}{|l|}{ SGRQ Scores, mean (SD) } \\
\hline Total & $48.0(17.5)$ & $49.2(18.7)$ & $49.2(18.5)$ & $50.2(17.6)$ & $50.4(17.9)$ \\
\hline Symptoms & $60.1(20.8)$ & $62.5(21.7)$ & $62.0(21.3)$ & $62.3(21.0)$ & $62.5(21.7)$ \\
\hline Activity & $65.3(19.8)$ & $64.5(22.5)$ & $65.1(22.4)$ & $67.8(20.0)$ & $67.7(20.2)$ \\
\hline Impacts & $34.4(19.5)$ & $36.3(19.5)$ & $35.9(19.3)$ & $36.4(19.6)$ & $36.8(19.2)$ \\
\hline
\end{tabular}

$\mathrm{COPD}=$ chronic obstructive pulmonary disease; $\mathrm{FEV}_{1}=$ forced expiratory volume in 1 second; $\mathrm{FVC}=$ forced vital capacity;

GOLDEN=Glycopyrrolate for Obstructive Lung Disease Via Electronic Nebulizer study; LABA=long-acting beta2-agonist; PIFR=peak inspiratory flow rate; $\mathrm{SD}=$ standard deviation; $\mathrm{SGRQ}=\mathrm{St}$ George's Respiratory Questionnaire.

${ }^{a}$ High cardiovascular risk included pre-existing diagnosis of ischemic heart disease, cerebrovascular disease, peripheral arterial disease, hypertension, clinically significant arrhythmia, and/or heart failure.

"In-Check was set to "no resistance" in GOLDEN-3 and -4 and to "resistance of HandiHaler" in GOLDEN-5.

and $86.3 \%(\mathrm{n}=402)$ in the glycopyrrolate/eFlow CS and tiotropium groups, respectively. Baseline patient characteristics were similar to those observed for the sample from the pooled efficacy studies (Table 1). Mean baseline SGRQ Total scores were similar in the glycopyrrolate/eFlow CS (50.38) and tiotropium (50.17) groups (Table 1), indicating high symptom burden and poor HRQoL at baseline.

\section{SGRQ Outcomes: Mean Change in Total and Component Scores from Baseline} Pooled GOLDEN-3 and -4

In GOLDEN-3 and -4, statistically significant improvements in SGRQ Total score were observed in 


\section{Figure 3a. Change from Baseline in SGRQ Total and Component Scores from Baseline to Week 12 in Pooled GOLDEN-3 and -4}

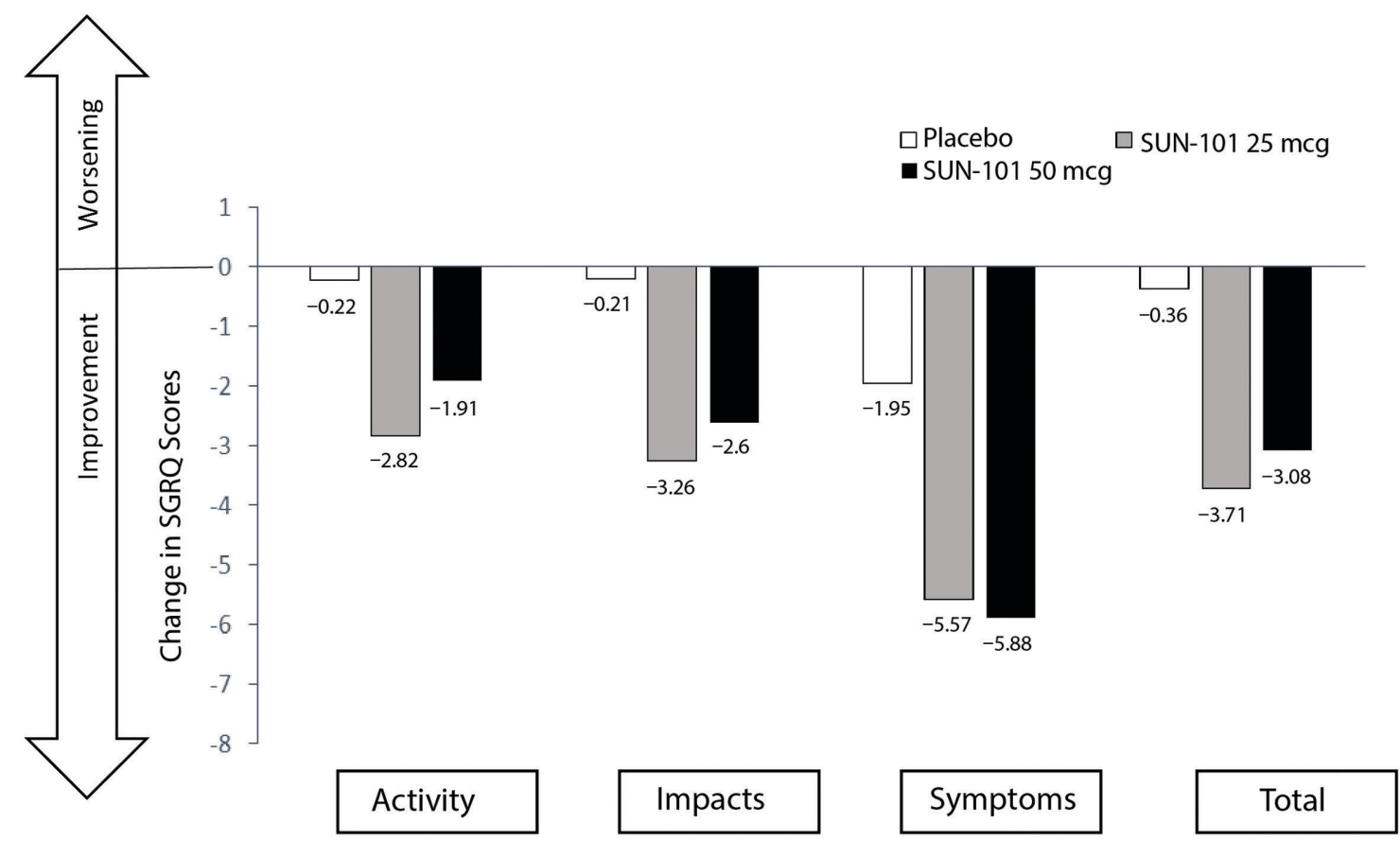

GOLDEN=Glycopyrrolate for Obstructive Lung Disease Via Electronic Nebulizer study; SGRQ=St George's Respiratory Questionnaire

patients receiving glycopyrrolate/eFlow CS (Figure 3a). Mean change at week 12 from baseline in Total score was greater for both glycopyrrolate/eFlow CS 25 mcg (least squares [LS] mean, -3.71 ; 95\% confidence interval [CI]: $-4.85,-2.57)$ and $50 \mathrm{mcg}(-3.08 ;-4.23$, -1.93) than placebo $(-0.36 ;-1.52,0.79)$ as shown in Figure 3a. The improvements in Total score for both glycopyrrolate/eFlow CS groups relative to the placebo group were statistically significant (placeboadjusted LS mean changes from baseline; 95\% CI: 25 mcg, -3.35; -4.90, -1.79; 50 mcg, -2.71; -4.28, -1.15).

Statistically significant improvements were also seen in the Symptoms, Impacts, and Activity component scores for patients treated with glycopyrrolate/eFlow CS as compared with placebo (Figure 3a). Mean changes at week 12 from baseline in the Symptoms component were greater for both glycopyrrolate/eFlow CS 25 mcg (LS mean, -5.57; 95\% CI: -7.24, -3.9) and $50 \mathrm{mcg}(-5.88 ;-7.56,-4.2)$ than with placebo (-1.95; -3.64, -0.27). The improvements in the Symptoms component with both glycopyrrolate/eFlow CS groups compared with the placebo group were statistically significant (LS mean difference versus placebo; 95\% CI: 25 mcg, -3.62; -5.9, -1.34; 50 mcg, -3.93; -6.2, -1.65).
Improvements from baseline to week 12 were also observed for glycopyrrolate/eFlow CS in the Impacts component (LS mean; 95\% CI: 25 mcg, -3.26; -4.52, -1.99 ; $50 \mathrm{mcg},-2.6$; $-3.87,-1.33$; placebo, -0.21; $-1.49,1.08)$; the mean change in scores for both glycopyrrolate/eFlow CS groups was significant compared with the placebo group (LS mean difference versus placebo; 95\% CI: 25 mcg, -3.05; -4.78, -1.33; 50 mcg, -2.40; -4.12,-0.67). Patients in the glycopyrrolate/ eFlow CS groups also experienced improvements at week 12 from baseline in the Activity component (LS mean; 95\% CI: glycopyrrolate/eFlow CS 25 mcg, -2.82 ; $-4.33,-1.31 ; 50$ mcg, $-1.91 ;-3.43$, -0.40; placebo, $0.22 ;-1.31,1.75)$, which were also significant for both glycopyrrolate/eFlow CS groups when compared with the placebo group (LS mean difference versus placebo; 95\% CI: glycopyrrolate/eFlow CS 25 mcg, -3.04; -5.10, -0.98 ; 50 mcg, $-2.13 ;-4.19,-0.07)$.

\section{GOLDEN-5}

In GOLDEN-5, improvements in Total scores were observed for glycopyrrolate/eFlow CS and tiotropium (Figure 3b). The mean (95\% CI) change in Total score from baseline at week 48 was $-3.1(-4.30,-1.84)$ for 


\section{Figure 3b. Change in SGRQ Total Score from Baseline in GOLDEN-5}



aValues are significant at $P<0.0001$.

GOLDEN=Glycopyrrolate for Obstructive Lung Disease Via Electronic Nebulizer study; SGRQ= St George's Respiratory Questionnaire

glycopyrrolate/eFlow CS and -4.1 (-5.41, -2.74) for tiotropium; the difference between groups was not statistically significant.

The mean (95\% CI) change from baseline at week 48 in the Symptoms component was $-5.76(-7.42$, -4.10) for glycopyrrolate/eFlow CS and -6.71 (-8.69, -4.73) for tiotropium (Figure 3c). Improvements from baseline at week 48 were also observed for the Impacts (glycopyrrolate/eFlow CS, -2.05 [-3.42, -0.69]; tiotropium, -3.70 [-5.14, -2.25]) and Activity (glycopyrrolate/eFlow CS, $-3.43 \quad\left[\begin{array}{lll}-4.90, & -1.96] \text {; }\end{array}\right.$ tiotropium, -3.38 [-5.04, -1.73]) components for both groups.

\section{SGRQ Outcomes: Responder Analyses}

\section{Pooled GOLDEN-3 and -4}

At week 12, a higher proportion of patients in the glycopyrrolate/eFlow CS 25-mcg group met the MCID criteria of responder (46.8\%) than the placebo (34.5\%) and glycopyrrolate/eFlow CS 50-mcg (41.7\%) groups. The odds of response were significantly greater in both glycopyrrolate/eFlow CS groups compared with the placebo group (odds ratio [95\% CI]: $25 \mathrm{mcg}$, 1.68 [1.24, 2.28]; $50 \mathrm{mcg}, 1.36$ [1.00, 1.85]). More patients in the placebo group experienced a $\geq 4$-point worsening in Total score than in the glycopyrrolate/
eFlow CS groups, and the percentage of patients with no change was generally similar across all groups (Figure 4a). The subgroup analyses showed a higher rate of responders for glycopyrrolate/eFlow CS $25 \mathrm{mcg}$ compared with placebo regardless of background LABA use, post-bronchodilator $\mathrm{FEV}_{1} \%$ predicted, PIFR, or age category at baseline (Figure 5a). Minor differences among subgroups were seen for SGRQ response in the glycopyrrolate/eFlow CS 50-mcg group compared with placebo, with the odds of response on SGRQ Total score being significantly greater in the 50 -mcg group as compared with placebo among subgroups of patients, with background LABA use, $<50 \% \mathrm{FEV}_{1} \%$ predicted, PIFR $\geq 60 \mathrm{~L} / \mathrm{min}$, and age $\geq 65$ years at baseline (Figure $5 b)$. In general, SGRQ responders were much higher in both glycopyrrolate/eFlow CS groups compared with placebo among patients on background LABA as compared with patients not on background LABA (odds ratio [95\% CI] for the 25 -mcg versus placebo groups: $2.30[1.2,4.2]$ in patients with background LABA, $1.4[1.0,2.0]$ in patients without background LABA; odds ratio [95\% CI] for the 50 -mcg versus placebo groups: $2.0[1.1,3.8]$ in patients with and 1.1 $[0.8,1.6]$ in patients without background LABA). 


\section{Figure 3c. Change in SGRQ Component Scores from Baseline in GOLDEN-5}

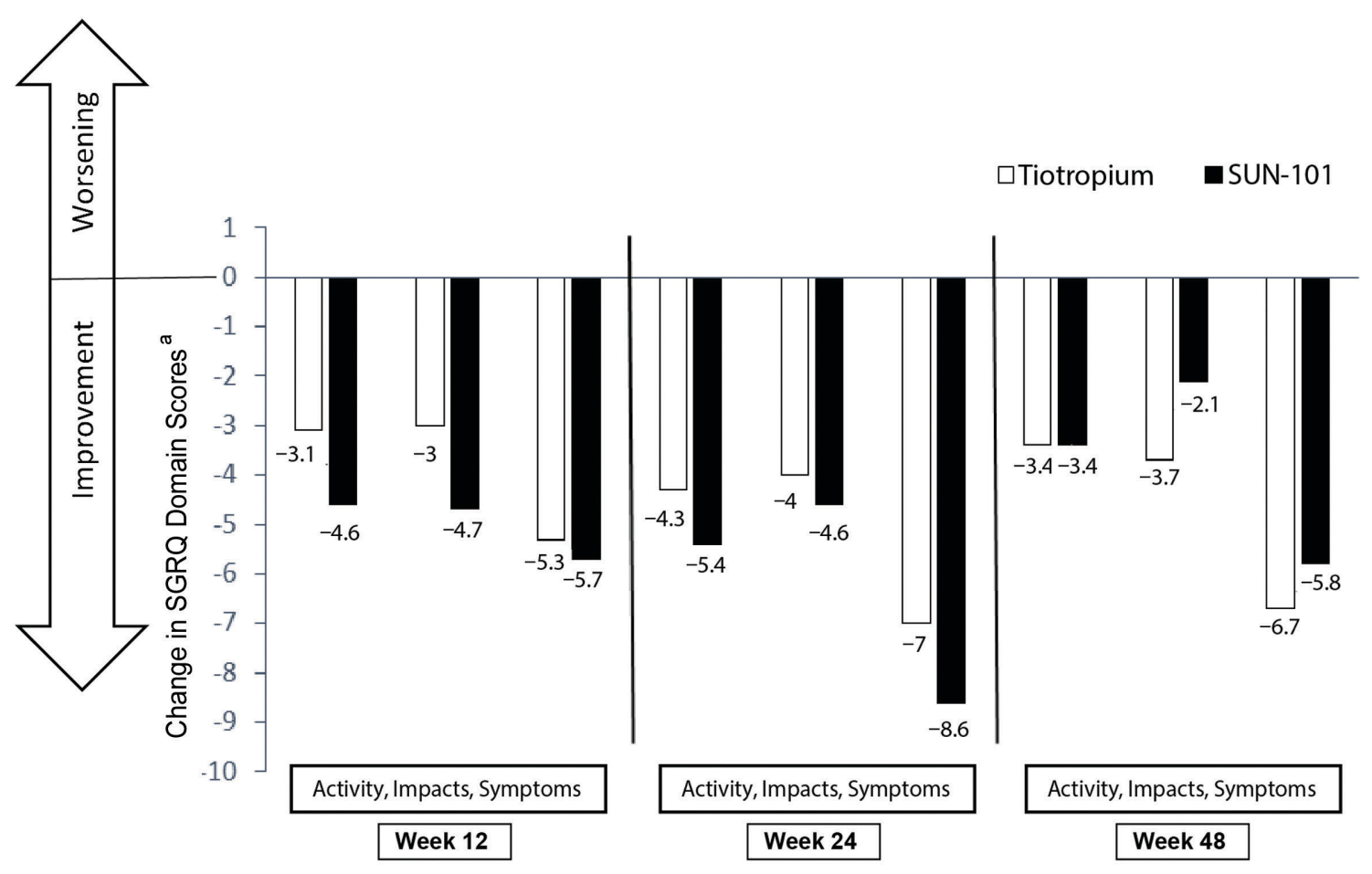

aAll values are significant at $P<0.05$.

GOLDEN=Glycopyrrolate for Obstructive Lung Disease Via Electronic Nebulizer study; SGRQ=St George's Respiratory Questionnaire

\section{GOLDEN-5}

Overall, the proportion of responders based on MCID criteria was similar between glycopyrrolate/eFlow CS and tiotropium groups. Proportions of responders were $50.1 \%$ and $45.4 \%$ at week $12,51.2 \%$ and $48.7 \%$ at week 24 , and $43.7 \%$ and $44.5 \%$ at week 48 in the glycopyrrolate/eFlow CS and tiotropium groups, respectively. Likewise, the proportions of patients with no change or $\geq 4$-point worsening in Total score were similar between the groups (Figure $4 \mathrm{~b}$ ).

\section{Discussion}

Glycopyrrolate/eFlow CS is a recently approved drug/device combination that is the first nebulized formulation of a LAMA available as maintenance treatment for patients with COPD. In the combined pivotal, phase 3 GOLDEN-3 and -4 studies, patients receiving glycopyrrolate/eFlow CS reported significant improvements in SGRQ Total and component scores at 12 weeks. The high rate of SGRQ responders in the placebo group could possibly be due to the Hawthorne effect - a positive impact or behavioral change seen among individuals as a result of participating in a trial or by knowing that they are being monitored. ${ }^{33,35}$ Further, roughly $30 \%$ of patients in the GOLDEN-3 and -4 studies were allowed to continue background LABA therapy, which might have also contributed to a clinically meaningful response in the placebo group. Regardless of the placebo response, however, the odds of achieving a clinically important improvement in SGRQ Total score (responder rate) were significantly higher in patients treated with glycopyrrolate/eFlow CS compared with placebo. These findings from the pooled GOLDEN-3 and 4 studies were consistent with those reported in the individual studies. ${ }^{30,36,37}$

Analysis of the pooled data also showed that deterioration of HRQoL based on SGRQ Total score was lower in the glycopyrrolate/eFlow CS groups as compared with the placebo group at week 12 . Additionally, subgroup analyses showed higher response rates in glycopyrrolate/eFlow CS $25 \mathrm{mcg}$ (i.e., the approved dose) as compared with placebo among all subgroups by age, $\mathrm{FEV}_{1} \%$ predicted, PIFR, or background LABA use at baseline. In the pooled sample, a greater reduction in magnitude of response on SGRQ Total score was observed for the 25-mcg dose as compared with the $50-\mathrm{mcg}$ dose, which is 


\section{Figure 4a. SGRQ Responder Rate in Pooled GOLDEN-3 and -4 at Week 12}



\footnotetext{
amproved $=\geq 4$-point decrease in SGRQ Total score; No Change $=-4<$ change $<4$-point change in SGRQ Total score; Worsened $=\geq 4$-point increase in SGRQ Total score.

SGRQ=St George's Respiratory Questionnaire
}

\section{Figure 4b. SGRQ Responder Rate in GOLDEN-5}



Improved $=\geq 4$-point decrease in SGRQ Total score; No Change $=-4<$ change $<4$-point change in SGRQ Total score; Worsened $=\geq 4$-point increase in SGRQ Total score.

SGRQ=St George's Respiratory Questionnaire

driven by the difference in SGRQ responses observed in the GOLDEN-3 study. Although there is a concern that additional symptoms may impair quality of life at higher doses, the pooled studies failed to demonstrate a statistically significant relationship between dose and HRQoL. The higher rate of SGRQ responders among patients on background LABA suggests that glycopyrrolate/eFlow CS may be an effective add-on treatment for patients who are on a previous LABA therapy, although this benefit needs investigation in a future clinical study. Combined with improvements in the primary endpoint and demonstrated safety as 


\section{Figure 5a. SGRQ Responder Rate by Subgroup in GOLDEN-3 and -4 (Glycopyrrolate/eFlow CS 25 mcg Versus Placebo)}

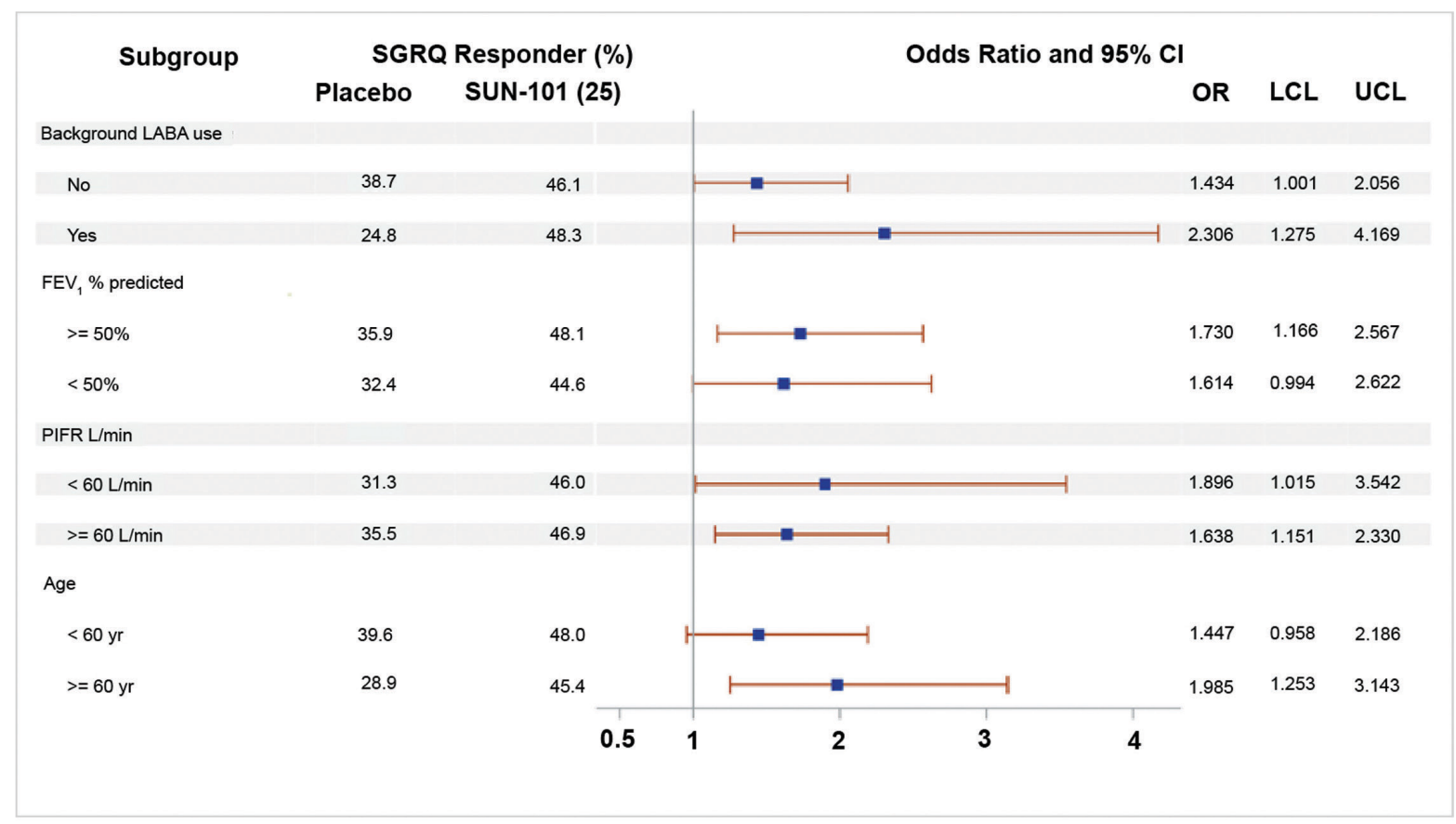

\section{Figure 5b. SGRQ Responder Rate by Subgroup in GOLDEN-3 and -4 (Glycopyrrolate/eFlow CS 50 mcg Versus Placebo)}

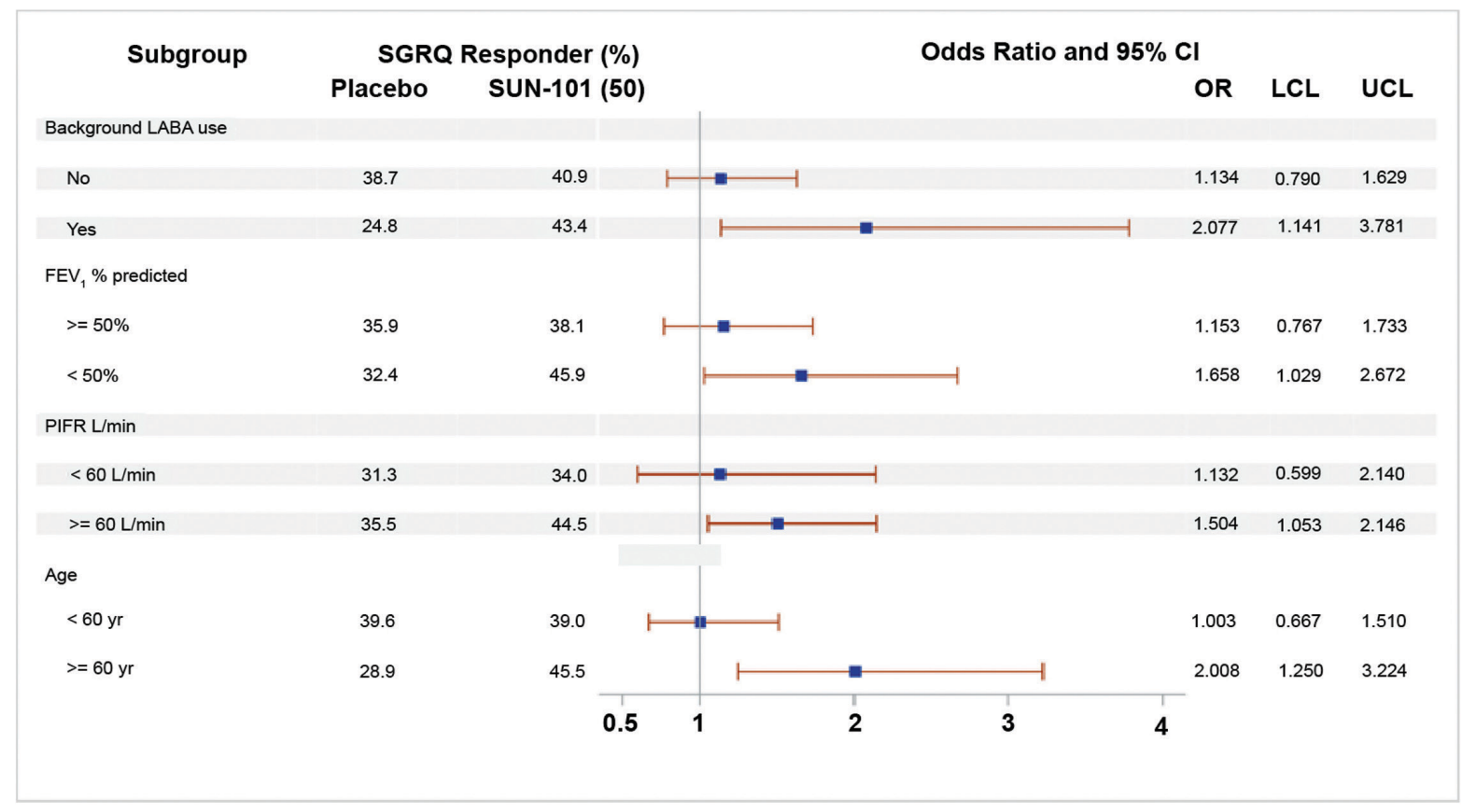

$\mathrm{CI}=$ confidence interval; $\mathrm{FEV}_{1}=$ forced expiratory volume in 1 second; GOLDEN=Glycopyrrolate for Obstructive Lung Disease Via Electronic Nebulizer study; LABA=long-acting beta2-agonist; OR=odds ratio; LCL=lower confidence limit; PIFR=peak inspiratory flow rate; SGRQ=St George's Respiratory Questionnaire; UCL=upper confidence limit 
discussed in previous publications, ${ }^{30,38}$ these findings show that nebulized glycopyrrolate/eFlow CS is a safe and efficacious treatment for long-term maintenance therapy in patients with moderate to very severe COPD. Previous studies involving other bronchodilators have shown that improvements in SGRQ Total score were significantly associated with a lower risk for COPD exacerbations, thereby underscoring the importance of SGRQ improvements beyond patient's health status. ${ }^{39}$ However, we note that the impact of nebulized glycopyrrolate/eFlow CS in reducing COPD exacerbations directly has not been studied.

It has to be noted that glycopyrrolate, as monotherapy for maintenance treatment of COPD is also available in the form of a DPI. The Glycopyrrolate Effect on syMptoms and lung function studies (GEM1 and GEM2) evaluated the efficacy and safety of glycopyrrolate $15.6 \mathrm{mcg}$ administered BID via DPI in patients with moderate to severe COPD. ${ }^{36,37}$ In these trials, glycopyrrolate produced significant improvements in SGRQ Total score and a higher percentage of treatment responders over 12 weeks compared with placebo. ${ }^{36,37}$ Some differences in patient characteristics between the GEM and the GOLDEN studies are notable. While the GEM studies included patients with moderate to severe COPD, the GOLDEN studies also included very severe patients, with lower post-bronchodilator baseline $\mathrm{FEV}_{1} \%$ predicted, background LABA use, and high $\mathrm{CV}$ risk. Despite these differences in the underlying population, the HRQOL findings in the GOLDEN studies were largely consistent with those observed in the GEM trials. These studies together ( $\mathrm{n}=866$ in GEM 1 and 2 and 1293 in GOLDEN-3 and -4) show that treatment with glycopyrrolate may lead to significant improvements in patients' HRQoL. Delivery of nebulized glycopyrrolate/eFlow CS offers an alternative for maintenance treatment of COPD patients who need a nebulized delivery option.

Results from GOLDEN-5 showed that the improvements in SGRQ scores and responders in the glycopyrrolate/eFlow CS 50-mcg group were similar to those observed in the tiotropium group, and these improvements were demonstrated in both treatment groups over 48 weeks. The open-label design of the GOLDEN-5 study may be perceived as a potential limitation to making comparisons between the 2 treatments. The responder rates observed with glycopyrrolate/eFlow CS from the GOLDEN-3 and -4 studies were in the similar range of those reported for other LAMAs in previous clinical trials. ${ }^{40,41}$ However, most of the prior LAMA studies were conducted in patients with moderate to severe COPD unlike the GOLDEN studies which, as mentioned previously, included a patient population that closely mimicked a real-world COPD population by including very severe patients, those with CV risk, and patients on background LABA. ${ }^{42-45} \mathrm{CV}$ disease is a common clinical comorbidity, and a high percentage of COPD patients are likely to have background treatment with a LABA or LABA/inhaled corticosteroid treatment in the real world. ${ }^{1}$

Among maintenance treatments available for COPD, currently only LABAs are available for nebulized delivery and hence there is a gap in therapy for COPD patients who may need a nebulized option for a LAMA, either as monotherapy or to be used in conjunction with a nebulized LABA. Glycopyrrolate/ eFlow CS may fill this gap in therapy. It is estimated that approximately $45 \%$ of COPD patients in the United States may be using a nebulizer, ${ }^{25,26}$ although most of its use is with short-acting agents, which are only intended for use as rescue medications. The GOLD guidelines recommend use of long-acting bronchodilators for routine maintenance treatment in moderate to severe COPD patients and also upon discharge from hospitalization for better outcomes. ${ }^{1}$ Nebulized treatments may especially be beneficial for elderly patients and patients who have difficulties with achieving adequate inspiratory flow, coordinating single-breath actuation, or holding breath for the required time after dose delivery. ${ }^{45}$ The eFlow CS nebulizer uses tidal breathing to deliver an acceptable respirable fraction of glycopyrrolate aerosol droplets into the lung within 3 minutes and is quite portable. The eflow CS is also designed such that patients can insert the glycopyrrolate drug vial directly into the nebulizer reservoir and hence preparation of the drug is not required, which in turn may minimize dosing errors. ${ }^{27}$ These attributes of the eFlow CS device are some of the advantages over the traditional jet nebulizers and may potentially improve medication adherence and outcomes in COPD patients.

\section{Conclusions}

In the GOLDEN studies, the investigational drug/device combination of nebulized longacting glycopyrrolate/eFlow CS $25 \mathrm{mcg}$ and $50 \mathrm{mcg}$, 
administered twice daily, resulted in significant improvements in HRQOL as measured by SGRQ in patients with moderate to very severe COPD. Nebulized glycopyrrolate/eFlow CS offers a potential alternative option for maintenance treatment of COPD patients.

\section{Acknowledgements}

Author contributions: R.T., V.B. and K.R. contributed to the study design. G.F. and E.K. contributed to data collection. All authors contributed toward the data analysis, interpretation of results and drafting and revising the manuscript, and agree to be accountable for all aspects of the work. Heather King, $\mathrm{PhD}$, and Claudette Knight, PharmD, of Percolation Communications LLC (Annandale, New Jersey) provided medical editorial support. Medical editorial support was funded by Sunovion Pharmaceuticals Inc.

\section{Declaration of Interest}

Sunovion Pharmaceuticals Inc., provided funding for this research.

G. Ferguson receives consultancy and advisory fees from Sunovion Pharmaceuticals Inc., E.M. Kerwin receives consultancy and advisory fees from Amphastar, AstraZeneca, Mylan, Novartis, Pearl, Sunovion, Teva, and Theravance. He has conducted multicenter clinical research trials for approximately 40 pharmaceutical companies. J. Donohue receives consultancy and advisory fees from Sunovion Pharmaceuticals Inc. R. Tosiello, V Ganapathy, and K. Rajagopalan are full-time employees of Sunovion Pharmaceuticals Inc. V. Bollu was a former full-time employee of Sunovion Pharmaceuticals Inc., and currently receives consultancy fees from Sunovion. 


\section{References}

1. Global Initiative for Chronic Obstructive Lung Disease (GOLD). Global strategy for the diagnosis, management and prevention of chronic obstructive pulmonary disease: 2017 report. GOLD website. https://goldcopd.org/gold-2017-global-strategy-diagnosismanagement-prevention-copd/ Published 2017. Accessed June 2018.

2. World Health Organization (WHO). Chronic obstructive pulmonary disease (COPD). Fact sheet. WHO website. http:// www.who.int/mediacentre/factsheets/fs315/en/.

Published November 2016. Accessed June 2018.

3. World Health Organization. Chronic respiratory diseases: burden of COPD. WHO website. http://www.who.int/respiratory /copd/burden/en/. Accessed June 2018.

4. National Heart, Lung and Blood Institute (NHLBI). Morbidity and mortality: 2012 chart book on cardiovascular, lung, and blood diseases. NHLBI website. https://www.nhlbi.nih.gov/files/docs/ research/2012_ChartBook_508.pdf February 2012. Accessed June 2018.

Published

5. American Lung Association (ALA). How serious is COPD: COPD prevalence in adults by state, 2015. ALA website. http:// www.lung.org/lung-health-and-diseases/lung-disease-lookup/ copd/learn-about-copd/how-serious-is-copd.html.

Published 2017. Accessed June 2018.

6. Kentson M, Todt K, Skargren E, et al. Factors associated with experience of fatigue, and functional limitations due to fatigue in patients with stable COPD. Ther Adv Respir Dis. 2016;10(5):410424. doi: https://doi.org/10.1177/1753465816661930

7. Jones PW. Activity limitation and quality of life in COPD. COPD. 2007;4(3):273-278.

doi: https://doi.org/10.1080/15412550701480265

8. Carrasco Garrido P, de Miguel Diez J, Rejas Gutierrez J, et al. Negative impact of chronic obstructive pulmonary disease on the health-related quality of life of patients. Results of the EPIDEPOC study. Health Qual Life Outcomes. 2006;4:31. doi: https://doi.org/10.1186/1477-7525-4-31

9. Jones PW, Brusselle G, Dal Negro RW, et al. Health-related quality of life in patients by COPD severity within primary care in Europe. Respir Med. 2011;105(1):57-66. doi: https://doi.org/10.1016/j.rmed.2010.09.004

10. Anzueto A, Leimer I, Kesten S. Impact of frequency of COPD exacerbations on pulmonary function, health status and clinical outcomes. Int J Chron Obstruct Pulmon Dis. 2009;4:245-251.

11. Seemungal TA, Donaldson GC, Paul EA, Bestall JC, Jeffries DJ, Wedzicha JA. Effect of exacerbation on quality of life in patients with chronic obstructive pulmonary disease. Am J Respir Crit Care Med. 1998;157(5):1418-1422.

doi: https://doi.org/10.1164/ajrccm.157.5.9709032
12. Kim JK, Lee SH, Lee BH, et al. Factors associated with exacerbation in mild- to-moderate COPD patients. Int J Chron Obstruct Pulmon Dis. 2016;11:1327-1333.

doi: https://doi.org/10.2147/COPD.S105583

13. Solem CT, Sun SX, Sudharshan L, Macahilig C, Katyal M, Gao $\mathrm{X}$. Exacerbation-related impairment of quality of life and work productivity in severe and very severe chronic obstructive pulmonary disease. Int J Chron Obstruct Pulmon Dis. 2013;8:641652. doi: https://doi.org/10.2147/COPD.S51245

14. Melani AS. Long-acting muscarinic antagonists. Expert Rev Clin Pharmacol. 2015;8(4):479-501.

doi: https://doi.org/10.1586/17512433.2015.1058154

15. Karner C, Chong J, Poole P. Tiotropium versus placebo for chronic obstructive pulmonary disease. Cochrane Database Syst Rev. 2014:Cd009285.

doi: https://doi.org/10.1002/14651858.CD009285.pub3

16. Kew KM, Mavergames C, Walters JA. Long-acting beta2agonists for chronic obstructive pulmonary disease. Cochrane Database Syst Rev. 2013:Cd010177.

doi: https://doi.org/10.1002/14651858.CD010177.pub2

17. Montuschi P. Pharmacological treatment of chronic obstructive pulmonary disease. Int J Chron Obstruct Pulmon Dis. 2006; 1:409423. doi: https://doi.org/10.2147/copd.2006.1.4.409

18. Rau JL. Practical problems with aerosol therapy in COPD. Respir Care. 2006;51:158-172.

19. Haidl P, Heindl S, Siemon K, Bernacka M, Cloes RM. Inhalation device requirements for patients' inhalation maneuvers. Respir Med. 2016;118:65-75.

doi: https://doi.org/10.1016/j.rmed.2016.07.013

20. Chrystyn H, van der Palen J, Sharma R, et al. Device errors in asthma and COPD: systematic literature review and metaanalysis. NPJ Prim Care Respir Med. 2017;27:22. doi: https://doi.org/10.1038/s41533-017-0016-z

21. Gray SL, Williams DM, Pulliam CC, Sirgo MA, Bishop AL, Donohue JF. Characteristics predicting incorrect metereddose inhaler technique in older subjects. Arch Intern Med. 1996;156(9):984-988.

doi: https://doi.org/10.1001/archinte.1996.00440090084008

22. Mahler DA, Waterman LA, Gifford AH. Prevalence and COPD phenotype for a suboptimal peak inspiratory flow rate against the simulated resistance of the Diskus(R) dry powder inhaler. $J$ Aerosol Med Pulm Drug Deliv. 2013;26(3):174-179.

doi: https://doi.org/10.1089/jamp.2012.0987

23. Loh CH, Peters SP, Lovings TM, Ohar JA. Suboptimal inspiratory flow rates are associated with chronic obstructive pulmonary disease and all-cause readmissions. Ann Am Thorac Soc. 2017;14(8):1305-1311.

doi: https://doi.org/10.1513/AnnalsATS.201611-903OC 
24. Sharma G, Mahler DA, Mayorga VM, Deering KL, Harshaw $\mathrm{O}$, Ganapathy V. Prevalence of low peak inspiratory flow rate at discharge in patients hospitalized for COPD exacerbation. Chronic Obstr Pulm Dis. 2017;4(3):217-224.

doi: https://doi.org/10.15326/jcopdf.4.3.2017.0183

25. Dhand R, Dolovich M, Chipps B, Myers TR, Restrepo R, Farrar JR. The role of nebulized therapy in the management of COPD: evidence and recommendations. COPD. 2012;9(1):58-72. doi: https://doi.org/10.3109/15412555.2011.630047

26. Tashkin DP. A review of nebulized drug delivery in COPD. Int $J$ Chron Obstruct Pulmon Dis. 2016;11:2585-2596. doi: https://doi.org/10.2147/COPD.S114034

27. Kerwin EM, Donohue JF, Ferguson GT, Ozol-Godfrey A, Ganapathy V. Patient device satisfaction with eFlow closed system nebulizer: results from the GOLDEN-5 study in patients with moderate-to-very severe chronic obstructive pulmonary disease (COPD). Am J Respir Crit Care Med. 2017;195:A1416.

28. Arr A. Jet, ultrasonic, and mesh nebulizers: an evaluation of nebulizers for better clinical outcomes. Eurasian J Pulmonol. 2014;16:1-7. doi: https://doi.org/10.5152/ejp.2014.00087

29. Ferguson GT, Goodin T, Tosiello R, Wheeler A, Kerwin EM. Long-term safety of SUN-101/eFlow ${ }^{\circledast}$ (nebulized glycopyrrolate) in moderate-to-severe COPD: results from the Glycopyrrolate for Obstructive Lung Disease via Electronic Nebulizer (GOLDEN) 5 study. Am J Respir Crit Care Med. 2017;195:A3588.

30. Kerwin E, Donohue JF, Goodin T, Tosiello R, Wheeler A, Ferguson GT. Efficacy and safety of glycopyrrolate/eFlow ${ }^{\circledR}$ (nebulized glycopyrrolate) in moderate-to-very-severe COPD: Results from the Glycopyrrolate for Obstructive Lung Disease via Electronic Nebulizer (GOLDEN) 3 and 4 randomized controlled trials. Respir Med. 2017;132:238-250. doi: https://doi.org/10.1016/j.rmed.2017.07.011

31. Global Initiative for Chronic Obstructive Lung Disease. Global strategy for the diagnosis, management and prevention of chronic obstructive pulmonary disease-2014 report. Research Gate website. file:///C:/Users/pc/Downloads/GOLD_Report_20 14_Jan231.pdf.Published 2014. Accessed June 2015.

32. Jones PW, Forde Y. St George's Respiratory Questionnaire Manual v2.3. 2009. St George's University of London website. http://www.healthstatus.sgul.ac.uk/SGRQ_download/ SGRQ\%20Manual\%20June\%202009.pdf

Published 2009. Accessed June 2018.

33. Jones PW, Beeh KM, Chapman KR, Decramer M, Mahler DA, Wedzicha JA. Minimal clinically important differences in pharmacological trials. Am J Respir Crit Care Med. 2014;189 (3):250-255. doi: https://doi.org/10.1164/rccm.201310-1863PP

34. Jones PW. St George's Respiratory Questionnaire: MCID. COPD. 2005;2(1):75-79.

doi: https://doi.org/10.1081/COPD-200050513
35. Hardin M, Rennard SI. What's new with the St George's Respiratory Questionnaire and why do we care? Chronic Obstr Pulm Dis. 2017;4(2):83-86.

doi: https://doi.org/10.15326/jcopdf.4.2.2017.0139

36. Kerwin E, Siler TM, Korenblat P, et al. Efficacy and safety of twice-daily glycopyrrolate versus placebo in patients with COPD: The GEM2 Study. Chron Obstr Pulm Dis. 2016;3(2):549559. doi: https://doi.org/10.15326/jcopdf.3.2.2015.0157

37. LaForce C, Feldman G, Spangenthal S, et al. Efficacy and safety of twice-daily glycopyrrolate in patients with stable, symptomatic COPD with moderate-to-severe airflow limitation: the GEM1 study. Int J Chron Obstruct Pulmon Dis. 2016;11:1233-1243.

38. Ferguson GT, Goodin T, Tosiello R, Wheeler A, Kerwin E. Longterm safety of glycopyrrolate/eFlow ${ }^{\circledR}$ in moderate-to-very-severe COPD: Results from the glycopyrrolate for obstructive lung disease via electronic nebulizer (GOLDEN) 5 randomized study. Respir Med. 2017;132:251-260. doi: https://doi.org/10.1016/j.rmed.2017.08.020

39. Martin AL, Marvel J, Fahrbach K, Cadarette SM, Wilcox TK, Donohue JF. The association of lung function and St George's respiratory questionnaire with exacerbations in COPD: a systematic literature review and regression analysis. Respir Res. 2016;17:40. doi: https://doi.org/10.1186/s12931-016-0356-1

40. Kaplan A. Effect of tiotropium on quality of life in COPD: a systematic review. Prim Care Respir J. 2010;19:315-325. doi: https://doi.org/10.4104/pcrj.2010.00067

41. Tashkin DP, Celli B, Senn S, et al. A 4-year trial of tiotropium in chronic obstructive pulmonary disease. $N$ Engl $\mathrm{J}$ Med. 2008;359:1543-1554.

doi: https://doi.org/10.1056/NEJMoa0805800

42. Gelb AF, Tashkin DP, Make BJ, et al. Long-term safety and efficacy of twice-daily aclidinium bromide in patients with COPD. Respir Med. 2013;107:1957-1965. doi: https://doi.org/10.1016/j.rmed.2013.07.001

43. Ni H, Soe Z, Moe S. Aclidinium bromide for stable chronic obstructive pulmonary disease. Cochrane Database Syst Rev. 2014:CD010509.

doi: https://doi.org/10.1002/14651858.CD010509.pub2

44. Ni H, Htet A, Moe S. Umeclidinium bromide versus placebo for people with chronic obstructive pulmonary disease (COPD). Cochrane Database Syst Rev. 2017;6:CD011897. doi: https://doi.org/10.1002/14651858.CD011897.pub2

45. Tashkin DP, Bateman ED, Jones P, et al. Consistent improvement in health-related quality of life with tiotropium in patients with chronic obstructive pulmonary disease: Novel and conventional responder analyses. Respir Med. 2016;120:91-100. doi: https://doi.org/10.1016/j.rmed.2016.10.002 